\title{
Aportaciones del texto a la edición crítica de una ópera: Las naves de Cortés, de Ruperto Chapí
}

\author{
Francisco Manuel LóPEZ \\ Universidad de Castilla-La Mancha \\ franmalogo@hotmail.com
}

\section{RESUMEN}

La edición crítica de música vocal plantea numerosos problemas relacionados con la adecuación del texto literario al musical, y para solventarlos el musicólogo debe conocer el contexto histórico-social y el pensamiento estético del compositor y del autor del libreto. En el caso de la ópera de finales del s. XIX, las discusiones sobre la relación entre música y texto fueron constantes, como ocurrirá en el contexto en torno al cual se compuso la obra de que nos ocupamos: Las naves de Cortés.

Una de las primeras tareas que debe asumir el editor de ópera es el análisis comparativo del libreto propuesto por el poeta y la adaptación realizada por el compositor; posteriormente, a la hora de establecer el texto es fundamental el análisis de la relación entre el material musical y el literario, lo que nos ayudará a tomar decisiones en aspectos relacionados con el ritmo, la dinámica, la agógica, las ligaduras de expresión o los signos de articulación. Los ejemplos que se ofrecen en torno a la edición de esta ópera en un acto de Chapí pretenden inducir a la reflexión en este sentido y, a su vez, abrir el camino a nuevas formas de abordar la edición de música vocal.

Palabras clave: edición musical, ópera española, Ruperto Chapí, Antonio Arnao.

\begin{abstract}
The critical editing of vocal music raises many problems related to the adaptation between literary texts and musical ones. Musicologists must have knowledge of historical context and both composer and author of the libretto aesthetical thoughts to save these problems. At the end of the nineteenth century, discussions about the relationships between musical and literary text were a constant feature in the opera genre. This situation took place in the context in which Las naves de Cortés was composed.

One of the most important aims which must be assumed by opera editors is the comparative analysis between the libretto written by the poet and the adaptation made by the composer. Then, it is necessary the analysis of the relationships between musical and literary works to the establishment of the text, what will help us to make decisions about rhythm, dynamics, expression slurs or articulation. This article offers some examples on this opera in one act by Chapí, in order to induce reflection and to pioneer new ways in critical editing of music.
\end{abstract}


Keywords: musical editing, spanish opera, Ruperto Chapi, Antonio Arnao.

Sumario: 1. Introducción 2. Contexto del surgimiento de la obra 3. Del libreto a la obra musical 4. Algunas consideraciones sobre la edición de Las naves de Cortés 5. Conclusiones

\section{Introducción}

La musicología ha recurrido desde sus comienzos a los métodos y enfoques de la crítica filológica para llevar a cabo sus ediciones textuales. En este sentido, a pesar de las diferencias semióticas existentes entre el texto musical y el literario, la metodología de la edición literaria ha servido de referente a la musicología ${ }^{1}$. Puesto que una gran parte del repertorio de música está concebido para ser cantado, es imprescindible ampliar el punto de mira mediante un acercamiento entre el trabajo del filólogo y el del musicólogo, pues el resultado de la edición dependerá de una buena comprensión de la unión del texto musical y el literario. Algunas de las últimas líneas de actuación en el campo de la musicología están dirigidas en este sentido, pudiendo encontrar no sólo estudios sobre influencias del texto literario a la composición musical y, por tanto, a la edición moderna, sino también préstamos de las composiciones musicales a la literatura ${ }^{2}$.

La adecuación de la música al texto ha sido una preocupación constante a lo largo de la historia, lo que ha generado en todo momento acaloradas discusiones acerca de qué material debería primar a la hora de componer una obra. Por tanto, cualquier edición debe partir del conocimiento de estos principios, que variarán de una época a otra. En este sentido, teniendo en cuenta la mayor o menor atención concedida por el compositor a la música o al texto, el editor deberá tomar dos tipos de decisiones: dar mayor relevancia al aspecto musical o tener presente en todo momento el texto literario para solventar los problemas que se presenten en cuanto a la notación musical se refiere. En el siglo XIX, un compositor de ópera debía atender tanto a los aspectos formales y métricos del texto como a los afectivos, debiendo tener el libreto siempre presente. Así, a pesar de que, en ocasiones, la música ya estuviera pensada por el compositor, este debía hacer las adaptaciones pertinentes cuando disponía del libreto.

Teniendo en cuenta esta premisa, para conseguir una buena edición crítica, a las tareas del cotejo, transcripción y establecimiento del texto musical se une la del análisis filológico, que se convierte, por tanto, y al igual que ocurría en el proceso de composición, en una labor previa para el editor de música.

${ }^{1}$ J. Grier (1996), p. 15.

2 Podemos consultar algunos estudios realizados en esta línea por el musicólogo y filólogo Pastor Comín: "Les introuvables: Don Lucas del Cigarral o la vindicación de una zarzuela olvidada" o "Fuentes musicales en la obra poética de Gutierre de Cetina". 
Las sugerencias que se plantean a continuación no pretenden servir como norma de actuación para todos los casos similares que se presenten en cualquier obra musical, puesto que cada testimonio es diferente, y el texto musical no equivale a la obra, sino que es una guía para el intérprete que está siempre en potencia y que se concretará en numerosos y distintos testimonios sonoros que se enmarcan, a su vez, en un momento concreto de la historia ${ }^{3}$. Así, el objetivo principal es inducir a la reflexión y mostrar la necesidad del análisis de todos los aspectos que rodean al hecho creativo.

\section{Contexto del surgimiento de la obra}

Para comprender mejor la obra, es necesario un conocimiento previo del estilo del autor y las condiciones socio-políticas que pueden dar explicación al hecho creativo. Así, realizaremos en primer lugar un repaso del contexto en el que surgió la obra que tomaremos como ejemplo: Las naves de Cortés.

En 1869 tuvo lugar un concurso cuyo objetivo era establecer la ópera nacional, para lo que se premiaron varias óperas de autor español y en lengua española, siendo seleccionadas dos para el primer premio: Atahualpa, de Enrique Barrera, y Don Fernando el Emplazado, de Valentín María de Zubiaurre. Este último compositor logró estrenar su obra en 1871 en el Teatro de la Alhambra, lo que puede considerarse un verdadero hito a partir del cual la composición de óperas españolas no cesó.

En este momento en el que fueron prolíficos los esfuerzos por fundar el nuevo género lírico, Antonio Arnao, poeta y autor del libreto de Las naves de Cortés, ingresó en la Academia de la Lengua en un momento en el que los esfuerzos por la creación de la ópera española fueron destacados, habiéndose planteado en varios medios las bases sobre las que cimentar el nuevo género. El mismo año de su ingreso (1873), se creó la Sección de Música de la Real Academia de Bellas Artes de San Fernando, uno de cuyos fines será conseguir la representación de óperas de autor español en el Teatro Real. Así, Arnao pronunció su discurso de ingreso titulado Del drama lírico y de la lengua castellana como elemento musical (30 de marzo de 1873) y, prácticamente al mismo tiempo, el poeta escribió el libreto Las naves de Cortés (salió a la luz casi un año después). Poco después (1875), publicó otros libretos que serían destinados al nuevo género: La muerte de Garcilaso, La hija de Jefté, La gitanilla, Guzmán el Bueno, Pelayo y Don Rodrigo, los dos primeros también puestos en música por Ruperto Chapí ${ }^{4}$.

De las nueve óperas citadas, ocho tratan un tema relacionado con la historia de España o con un personaje español destacado (La hija de Jefté trata un tema bíblico). Esto se explica en el contexto en el que fueron creadas, es decir, durante el sexenio democrático, que promovió la articulación de un sentimiento español pa-

${ }^{3}$ J. Grier (1996), pp. 20-24.

${ }^{4}$ A. Arnao (1875). 
triótico que buscaba la regeneración o revalorización de lo que se denominó 'cultura española', 'historia española', 'sentimiento español', etc. Así, con la fundación del género nacional se conseguiría un espectáculo en el que la música podría alcanzar su mayor grado de esplendor y del que carecía España (a diferencia de otras naciones europeas como Italia, Francia, Alemania, Rusia e Inglaterra); y uno de los pilares que se consideraba fundamental en este contexto del nacimiento del nacionalismo era el dar a conocer los logros históricos realizados por la nación española.

El 10 de noviembre de 1873 la Real Academia de Bellas Artes aprobó las bases de un concurso-oposición para proveer una plaza de pensionado en la recién creada Sección de Música en Roma ${ }^{5}$. Una de las pruebas consistió en poner música a un cuadro lírico, para lo que fue seleccionado el libreto de Arnao Las naves de Cortés. El fin seguía siendo, por tanto, el establecimiento de la ópera nacional y, con ello, el engrandecimiento del arte lírico español. Ruperto Chapí, que se formó estudiando tanto ópera italiana (Donizetti, Bellini y Verdi) como francesa (destacando Gounod y Meyerbeer), primero de forma autodidacta y después con Emilio Arrieta en el Conservatorio de Madrid, se presentó al concurso y consiguió el premio por unanimidad del jurado. Su profesor de composición, Arrieta, consiguió que el empresario del Teatro Real, Teodoro Robles, accediera a representar la ópera, con lo que Chapí pudo ver estrenada su obra el 19 de abril de 1874. Tras este éxito y como fruto de su pensionado, puso música a los otros dos libretos de Arnao antes mencionados ${ }^{6}$.

\section{Del libreto a la obra musical}

Por lo general, la mayoría de los compositores de ópera, si no han creado ellos mismos el texto, han adaptado el libreto del que disponían para conseguir un determinado efecto dramático o musical, o para cumplir unas determinadas exigencias para con los cantantes o el empresario del teatro. En este sentido, nos encontraremos con adaptaciones o modificaciones, cortes o añadidos del texto original.

En el discurso de su ingreso (Del drama lírico y de la lengua castellana como elemento musical), Arnao trató este tema y aportó una serie de propuestas para la creación de un libreto de ópera en español, las cuales aplicó en sus libretos ${ }^{7}$. Su análisis resulta de interés para comprender la importancia que se concedía a la relación entre música y texto:

Así, pues, habrá el oído de juzgarlos [los versos] inexorablemente para dejarlos en tal concepto limpios de toda aspereza de estructura, previniendo siempre las necesidades de la música, como, por ejemplo, la de no colocar al fin de un período poé-

\footnotetext{
${ }^{5}$ Real Academia de Bellas Artes de San Fernando (Madrid). Acta del día 10 de noviembre de 1873, pp. 581-582.

${ }^{6}$ L. Iberni (2006), pp. 37-61.

${ }^{7}$ S. López Gómez (1987), p. 155.
} 
tico, o de una estrofa donde probablemente ha de recaer la resolución de una frase musical, palabra cuya vocal acentuada sea poco sonora, como la $u$ o la $i^{8}$.

[...] sobre ser los períodos muy largos de difícil ejecución, hay que tener en cuenta las perífrasis y repeticiones de la música [...] También lo es la discreción en variar o no con rapidez la expresión de los sentimientos, porque tan expuesto será a la confusión musical el acumular diferentes en corto número de versos, como ocasionado a la monotonía el dar a una larga tirada de ellos el mismo colorido. Igualmente pide tino y prudencia el punto de la variación de metros, porque así como el estacionarse en cualquiera de ellos engendraría música demasiado uniforme, la demasiada movilidad y extravagancia de combinaciones engendraría a la vez cierta quietud de tiempos y compases ${ }^{9}$.

A la hora de elaborar el libreto, Arnao siguió los principios que estableció en su discurso de ingreso poco tiempo antes (el 30 de marzo de 1873). Así, defendía el uso del castellano escrito en verso, e insistió en lo importante que era que el poeta tuviera unos conocimientos básicos del género musical en sí mismo, pues debía pensar en la versificación de los futuros números musicales y en situaciones que permitieran una adecuada musicalización ${ }^{10}$. El libreto, por tanto, tal y como indica el propio poeta, no debía centrarse en aspectos metafísicos, sino simplemente imitar los afectos, procurando conseguir una variedad dramática para romper la uniformidad musical. Vemos en la obra de Arnao una gran variedad de situaciones, pues contrapone momentos de verdadera tranquilidad e incluso coloristas y costumbristas (primera escena) con otros de tensión dramática y conspiración (escena segunda) y con momentos llenos de dulzura, como la declaración de amor entre los protagonistas (escena tercera). A esto se une la gran variedad métrica, que va desde las licencias que el autor se permite en momentos concebidos para el recitado hasta la más rigurosa rigidez y paralelismo formal en escenas pensadas para un dúo, trío de personajes, etc.

En cuanto al aspecto fonético, Arnao también aplicó los principios que estableció y que hemos apuntado más arriba. En efecto, encontramos una gran variedad en la distribución de los acentos (para proporcionar al compositor la ocasión de utilizar distintos ritmos) y, a su vez, un uso casi exclusivo de vocales abiertas al final de cada estrofa.

Estos aspectos facilitaron la labor de Chapí, quien supo entender las convenciones dramáticas que utilizó el poeta, la variedad métrica y de situaciones que consiguió para construir una obra original en unos momentos e inspirada en las convenciones de la ópera italiana por números en otros.

\footnotetext{
${ }^{8}$ A. Arnao (1873), p. 20.

${ }^{9}$ A. Arnao (1873), p. 23.

${ }^{10}$ A. Arnao (1873), pp. 12-13.
} 
En consecuencia, para realizar la edición crítica de una obra de música vocal, sería útil presentar no sólo el texto que se desprende de la partitura o el que concibió el poeta, sino que lo ideal en este sentido sería presentar una nueva edición contrastada del libreto original con el texto que se puede extraer de la música, lo que puede constituir un documento de gran utilidad para su posterior análisis musicológico. De esta manera podremos observar si el compositor ha decidido prescindir de determinados personajes, intercambiar sus papeles (poniendo en boca de un personaje el texto de otro), modificar el orden del texto original para conseguir un determinado efecto dramático, cambiar una expresión por otra que considera más apropiada o que encaja mejor en la concepción musical del conjunto vocal, o añadir texto para atender al drama o, simplemente, a la frase musical.

Para exponer algunos de los problemas que se nos pueden presentar a la hora de editar las partes vocales de una partitura, utilizaremos como ejemplo el libreto y la partitura de la ópera en un acto Las naves de Cortés. El libreto fue publicado por Arnao en la Revista europea el 22 de marzo de $1874^{11}$, con lo que no plantea problemas para su edición. Sin embargo, el único testimonio que se conserva completo $^{12}$ no es autógrafo de Chapí, sino que fue escrito de la mano de varios copistas del Teatro Real para su representación ${ }^{13}$. La ventaja que ofrece este tipo de documentos es el hecho de ser destinados para su uso y el haber sido, efectivamente, utilizados (puesto que se trata de una obra que fue representada), con lo que presentan ya correcciones realizadas por los músicos (o, en su caso, por el propio director), quienes identificaron los errores cometidos. En la mayoría de las ocasiones estas correcciones ofrecen una solución adecuada al error que se presenta y, por tanto, son de gran ayuda para el editor, quien, no obstante, tiene que valorarlas respetándolas u ofreciendo una propuesta nueva. Una vez cotejados los dos testimonios, en los casos en los que los problemas y erratas han persistido, las enmiendas se han tenido que realizar ope ingenii; no obstante, contamos con varias copias de determinados instrumentos, como los de cuerda y las voces del coro, documentos que presentan variantes y que deben ser contrastados al mismo nivel de importancia al no existir un arquetipo.

En primer lugar, se deben contrastar el libreto y el texto presente en la partitura, con lo que encontramos en este caso los siguientes cambios:

- Sustitución de una o varias palabras del libreto por otras. En el verso $n^{0} 7$ : cruzan > vuelan. La razón del cambio puede ser el simple deseo de dar varie-

\footnotetext{
${ }^{11}$ A. Arnao (1874), pp. 103-105.

${ }^{12}$ R. Chapí [1874].

${ }^{13}$ Se conserva una copia de las partes de Cortes y del Capitán Escudero, junto con algunas partes de tiple $1^{\mathrm{a}}$ y $2^{\mathrm{a}}$ en el Real Conservatorio Superior de Madrid (RCSM 1_5632), que presentan variantes tanto en la música como en la letra, pero que no ofrecen posibles soluciones a algunos de los problemas que presenta el manuscrito que se conserva completo en el Museo Nacional del Teatro (MNT 1433).
} 
dad al texto, pues este verso lo repite tres veces a lo largo de la partitura. Más adelante (verso $\mathrm{n}^{\mathrm{o}} 55$ ) Nunca supe temer $>$ iNo temo riesgos yo!. Aquí utiliza Chapí la exclamación, junto con el pronombre personal y la repetición del sustantivo riesgo (aparece en el verso anterior -¿Qué riesgo se avecina?-), para dar mayor énfasis a la valentía de Cortés.

- Adición de texto. Después del verso n ${ }^{\circ} 19$, Chapí añade un verso partido que le sirve al Capitán para confirmar que sus soldados comparten su malestar y que van a apoyarlo en su traición a Cortés. A su vez, hace hincapié en la palabra eterna, enfatizando así el largo tiempo que llevan fuera de su tierra natal y sus deseos de regresar: (Capitán) ¿y nuestra patria? | (soldados) Eterna es su memoria $\mid>$ [añadido por Chapí] (Capitán) ¿Eterna? | (soldados) Si, eterna es. En el número 3 de la ópera, en el dúo de Cortés y Marina, la ampliación del texto obedece a una cuestión puramente musical: ;Guárdete el cielo! (v. 72), ;Guarde a los dos! (v. 73) y Yo por ti velo (v. 74) tienen un tratamiento imitativo de las voces; para conseguir un final del recitativo más conclusivo y dar paso al aria, resolviendo en la tonalidad, los dos amantes deben cantar a la vez, con lo que era necesario añadir un verso (;Guárdete Dios!, que coincide en la voz de Cortés con Páguete Dios -verso 76-), y otro más para finalizar en homofonía (El cielo guarde a los dos). Más adelante (versos 78 y 86) encontramos añadida una interjección (;Ah!) que tiene la función de llamar la atención del público para introducir un fragmento importante (el aria, de carácter reflexivo y de mayor importancia musical) y de dar unidad al discurso musical, puesto que Cortés cantará la misma melodía que Marina pero con texto diferente. Este tratamiento lo facilitan las cuartetas octosilábicas, que permiten repetir el mismo ritmo y melodía. A su vez, permitirán a Chapí finalizar el dúo conjuntamente, puesto que las dos cuartetas que canta Marina son idénticas a las de Cortés, al tener la misma métrica y utilizar de manera paralela la misma rima, posibilitando la homofonía y destacando el final de la frase musical al terminar ambos con la misma vocal.

- Omisión de texto. En ocasiones, el compositor considera que un fragmento del texto no es relevante para el drama, pues no cambia el desarrollo de los acontecimientos. En tal caso, prefiere afianzar el resto de la trama repitiendo fragmentos de texto, ya que la repetición es un rasgo intrínseco a la música. Así, en la escena primera Chapí omite los versos 13-16 ( $Y$ en plácido arrullo $\mid$ $y$ en blanco rumor, | vaga en torno suave murmullo, | cual eco de amor.) puesto que ya ha utilizado de manera independiente un coro de mujeres (indias) y otro de hombres (soldados) y luego la totalidad del coro, tal y como aparece en el libreto. Ya que el drama sólo avanza de forma más rápida en los recitativos, no aptos para las masas corales, el texto asignado al coro debe ser reducido (aún más en una obra de pequeñas dimensiones), con lo que el compositor vio necesario prescindir de este fragmento. Lo mismo ocurre con la omisión de los dos últimos versos (;Por la cruz redentora del hombre! | iPor 
el rey, por la patria, por Dios), aunque podría haber una explicación ideológica, puesto que la obra se compuso en el período de la Primera República, con lo que Chapí decidió suprimir alusiones religiosas y a la monarquía.

- Cambio del orden de los versos. En la escena segunda, los soldados, convencidos por el Capitán para regresar a España a toda costa, comienzan diciendo en el libreto ;Oh, noble caudillo! | Dijiste muy bien (versos 38-39), pero Chapí empieza el diálogo con los dos versos siguientes (Al punto veamos $\mid$ al fiero Cortés). El motivo es el juego musical que consigue a continuación al superponer la voz del Capitán con la de los soldados; de esta forma, mientras éste pronuncia Pues tornemos, joh amigos!, a España, los soldados cantan ¡Oh, noble caudillo! Dijiste muy bien, que produce un mejor efecto que cantado junto a Al punto veamos al fiero Cortés. Esto ocurre también en los versos 42-43, lo que otorga más relevancia a este momento (si soberbio se opone con saña $\mid$ bajo el hierro sucumba Cortés), que en el libreto lo protagonizaba sólo el Capitán, mientras que en la partitura participan, posteriormente, también los soldados. En la escena sexta, en la que tiene lugar la quema de las naves, las dos cuartetas del Capitán (versos 141-149), que expresan su rendición ante Cortés, aparecen en orden inverso en la partitura; puesto que Chapí otorga más importancia a la primera (Gran Cortés, a ti me inclino...), la reserva para el final del trío entre el Capitán, Cortés y Marina, al que se unen los soldados, lo que acentúa el efecto de la escena y, por tanto, el significado del texto.

- Intercambio del papel de los personajes. En la escena tercera, los versos 5153 (Aqui me trajo el cielo | que me enseñaste a ver, para pagarte | tus nobles beneficios, y salvarte), en boca de Cortés en el libreto, parecen un error de edición de la obra de Arnao (el personaje aparece mencionado dos veces consecutivas), pues es lógico pensar que es Marina la que va a salvar a Cortés al poder informarle de la conspiración existente contra él; además, con este cambio se acentúa el destacado papel romántico de la amada al aparecer como venida del cielo. Efectivamente, Chapí introduce este cambio de personaje. Finalmente, encontramos momentos en los que el compositor pone el texto en boca de varios personajes y en momentos distintos para conseguir fragmentos corales de mayor amplitud, con lo que el fin es puramente musical (para conseguir mayor variedad o un final con una mayor amplitud orquestal). La escena cuarta la concibió Arnao como un diálogo entre el Capitán y los soldados, pero Chapí quiso darle un tratamiento coral, con lo que eliminó el personaje del Capitán, que adquiriría, de lo contrario, mayor protagonismo en la obra que el propio Cortés, reservando así su aparición hasta el trío del último número de la ópera. Al himno final, protagonizado en el libreto por Cortés y los soldados, añade Chapí las figuras del Capitán y Marina, a los que se unen las indias, de forma que aparecen todos los personajes 
cantando la coda final de la ópera, consiguiendo una mayor majestuosidad y ofreciendo un mayor carácter conclusivo.

\section{Algunas consideraciones sobre la edición de Las naves de Cortés}

La premisa fundamental para cualquier edición es la de acercarse con el mayor grado de fidelidad a la idea original del autor, sin despreciar por ello la valiosa información que nos pueden ofrecer testimonios tanto anteriores (es el caso del libreto de Arnao) como posteriores o derivados de un modelo. En cuanto al momento de la constitutio textus, uno de nuestros objetivos debe ser el de facilitar la lectura al intérprete, sobre todo cuando se trata de un texto musical. Para este fin, en la edición de música es más útil prescindir de cualquier anotación al pie de página, pudiéndose aclarar las variantes y correcciones en el aparato crítico, mientras que las observaciones, decisiones de edición, orientaciones para la interpretación, etc. pueden incluirse en los criterios de edición ${ }^{14}$.

Existan o no varios testimonios, los distintos componentes de la música requieren una atención diferente. En el caso de una obra lírica, las dificultades se presentan sobre todo en la edición de las partes vocales solistas. Aunque las cuestiones relacionadas con la altura se salvan observando el conjunto orquestal (mediante un análisis armónico o, simplemente, contrastando el dibujo melódico con otros motivos similares u observando la dirección que sigue), todo aquello relacionado con el ritmo, las ligaduras de expresión y la articulación de las notas musicales requiere un estudio meticuloso de la adecuación del verso literario y la frase musical. Para ilustrar mejor las reflexiones que se ofrecen, se presentan a continuación algunos ejemplos sacados de la edición de Las naves de Cortés, que presenta erratas derivadas del apógrafo que se conserva:

- Adecuación del ritmo musical a la métrica literaria. Cuando el número de sílabas del texto es menor que el de notas musicales no existe ningún problema, puesto que las sílabas se prestan a poderles ser asignadas varias notas musicales. Sin embargo, cuando nos encontramos con más sílabas que notas musicales sin la posibilidad de recurrir a la sinéresis o la sinalefa, debemos añadir las figuras musicales necesarias. La solución más adecuada es recurrir a un ritmo distinto, manteniendo las alturas musicales. En la parte de Cortés (compases 195-196 del $\mathrm{n}^{\circ} 5$ de la ópera) nos encontramos en el manuscrito con diez sílabas (triun - fo - vo - le - mos, - vo - le - mos - en - pos) adscritas a nueve figuras musicales; la solución ha consistido en sustituir el grupo de una corchea con puntillo - semicorchea por un grupo de corchea - dos semicorcheas:

${ }^{14}$ J. Grier (1996), pp. 172-175. 


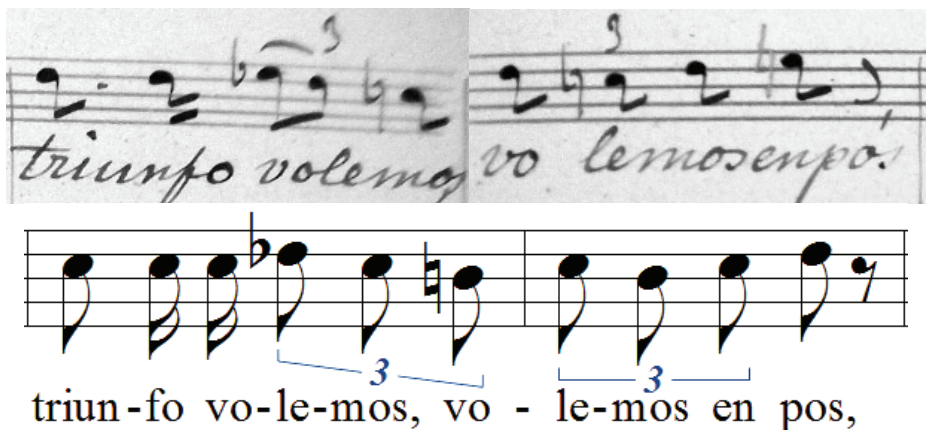

Este cambio se justifica, a su vez, contrastando el fragmento con el que aparece dos compases antes exactamente con las mismas sílabas:

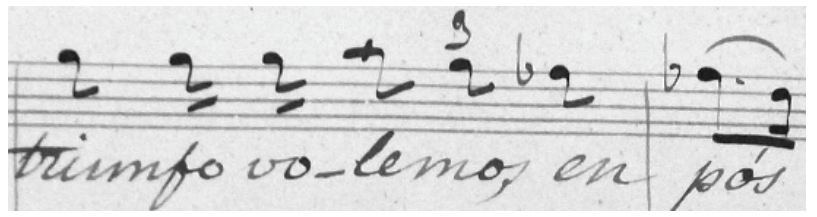

- Relación entre las ligaduras de expresión y el tratamiento silábico o melismático del texto. Puesto que la ligadura a lo largo de esta obra se utiliza para abarcar un melisma (al ejecutarse varias notas de un golpe de voz), cuando separamos una sinalefa convirtiéndola en un hiato la ligadura debe desaparecer, cambiando por tanto la ejecución musical. Un ejemplo lo encontramos en el último número de la ópera (número 5), en el compás 96 de la parte de Cortés: existe una contradicción en la partitura manuscrita entre el uso de la ligadura de expresión y la aplicación del hiato entre las sílabas 'o' y 'el', con lo que se ha procedido a suprimir la ligadura para conservar el hiato:

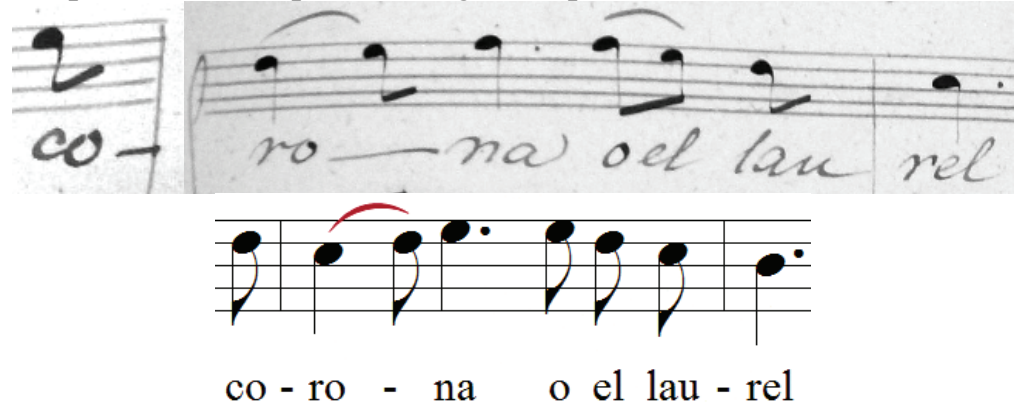

- Adaptación de la articulación musical a la acentuación del texto. En la mayoría de las ocasiones los signos de articulación se regularizan contrastando todas las voces de la orquesta, pero en otros casos es el texto el que nos indica la presencia de un error al no concordar el acento prosódico con el musical o, incluso, contradecirlo. En el compás 119 del último número de la ópera, la 
parte del Capitán presenta un error de este tipo, pues se ha situado un acento musical $(<)$ sobre la preposición 'a', cuando en el resto de voces no aparece; por este motivo, se ha suprimido dicho acento en la edición moderna de la ópera:
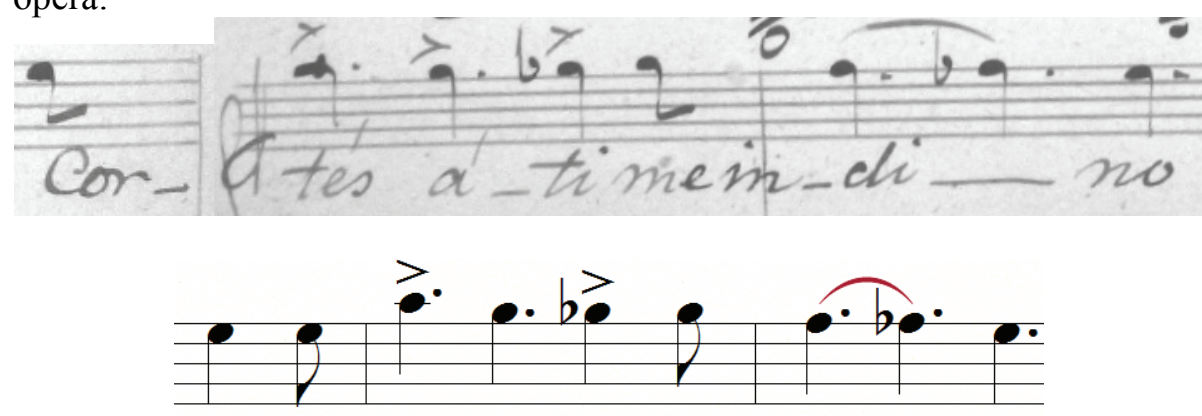

Gran Cor - tés, a ti me in - cli - no

- Adscripción de las sílabas del texto a las notas musicales atendiendo al acento textual y musical y a la relación entre la métrica y el ritmo musical. En el último número, el compás 20 (parte de Cortés) podría parecer correcto si atendemos a la relación métrica-ritmo; observamos que la frase ¿Qué hacéis? podría tener una sinalefa y una sinéresis, aunque, al haber tres notas, una de ellas debe ser obviada; en el manuscrito nos encontramos con la solución ¿Qué - ha - céis?, pero esto supondría que la sílaba 'ha' (átona) recayera en la parte fuerte del pulso, reservando la parte débil para 'céis'; por tanto, conviene introducir el cambio ¿Quéha - cé - is?, cayendo la penúltima sílaba en la parte fuerte del pulso:

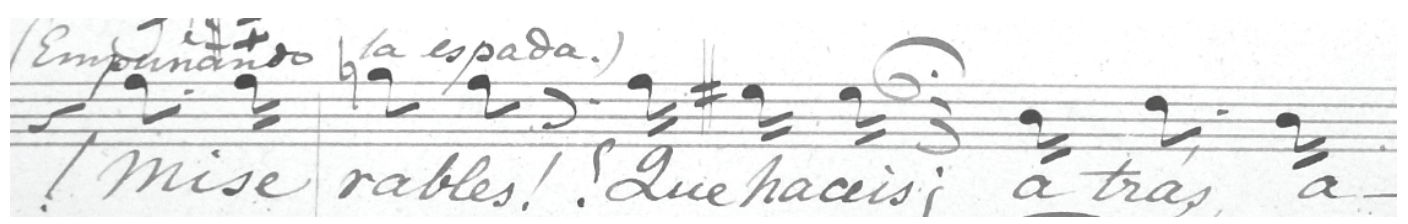

Empuñando la espada

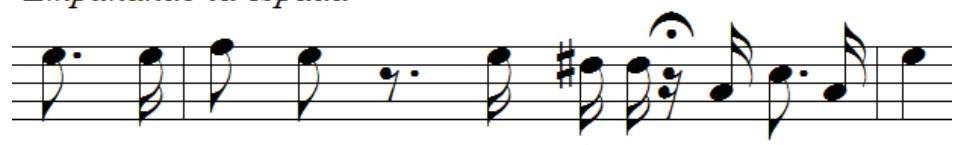

¡Mi - se - ra - bles! ¿Qué ha cé-is? ¡A-trás, a - trás!

En el número 3 de la ópera, compases 83-84 (parte de Cortés), la letra se ha adelantado una nota, error que se observa ya al final del compás 83 , pues para las dos últimas notas (corchea con puntillo - semicorchea) hay asignadas tres sílabas. La solución que se ha dado ha sido retrasar la sílaba 'nun' (de la pa- 
labra 'nunca') del final del compás 83 al inicio del 84, con lo que la sílaba tónica recae ahora sobre la parte fuerte del compás; a continuación, la sílaba
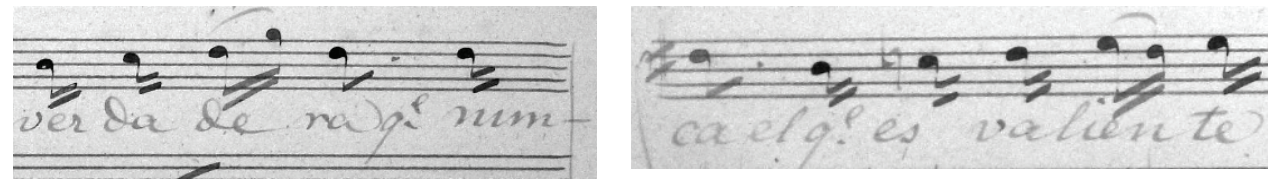

'ca' se uniría por sinalefa a 'el' y, después, 'que' a 'es', finalizando luego el compás conforme aparece en el manuscrito:

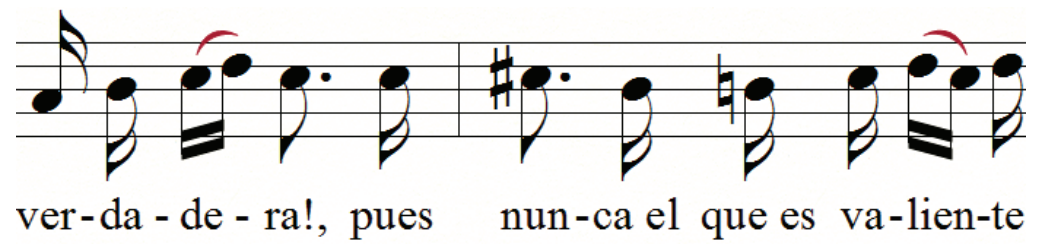

En otras ocasiones, se debe recurrir al hiato en la partitura (cuando en el texto la métrica exige una sinalefa) debido al ritmo con que nos encontramos. Así, en la parte de Cortés (número 3 de la ópera, compás 158) hallamos tres notas distintas para las palabras 'te amará'. Aunque en el manuscrito se unen por sinalefa 'te' y 'a', se ha decidido separarlas y evitar el melisma de dos notas, puesto que, a efectos prácticos, esta interpretación daría como resultado la doble dicción de la sílaba 'a':
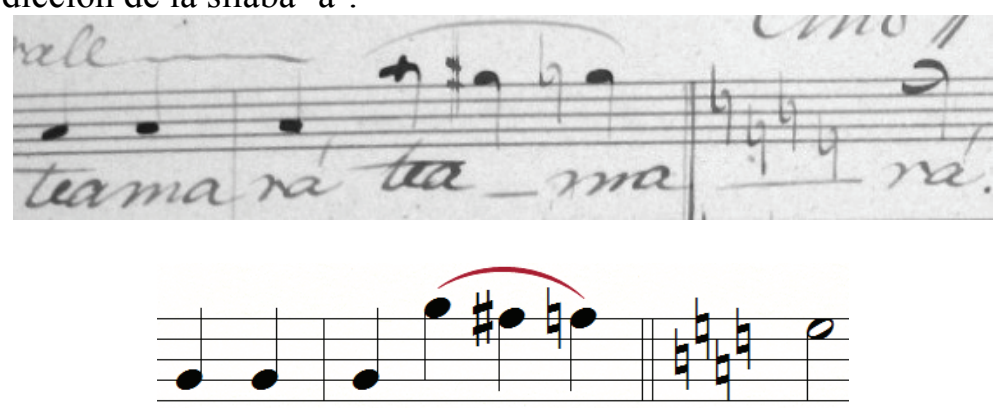

te a-ma - rá, te a-ma - rá.

\section{Conclusiones}

La ecdótica ha ido aportando nuevos métodos y observaciones a la edición de textos que, más allá de ser excluyentes, proporcionan al editor diversas herramientas que deberá utilizar para llegar a una mejor comprensión de la obra. Cada obra nos ofrecerá interrogantes cuya respuesta no la proporciona un manual de crítica textual, sino que nos obligará al planteamiento de una metodología específica que se ajuste a sus características y a la historia de los testimonios en los que ha pervi- 
vido. En todo caso, el editor debe estudiar el estilo del compositor para sacar conclusiones con respecto a la importancia o no que concede a la relación entre música y texto. A su vez, cada género, tanto literario como musical, requiere ser abordado teniendo en cuenta las características que lo definen. En el caso de la ópera por números, debemos diferenciar las secciones en las que el tratamiento de lo textual cobra un papel primordial (como en los recitativos o scenas) de aquellas en las que la línea melódica prima sobre el texto (como en algunas arias, romanzas o similares, o en los fragmentos con tratamiento estrófico, donde no existe una verdadera adaptación de la música al texto), en cuyo caso el compositor puede sacrificar la adecuación entre el acento musical y textual y los aspectos relacionados con la articulación.

El contraste del libreto original con las modificaciones (conscientes e inconscientes) nos permitirá obtener información sobre el estilo del compositor y la concepción que éste tenía sobre el género musical y la obra en particular. A su vez, el contraste del texto literario y el musical nos llevará a sacar conclusiones sobre la manera de componer del autor y, por tanto, nos servirá de gran ayuda para solucionar algunos problemas que se nos planteen en la edición de las partes vocales y, así, establecer el texto final.

\section{Obras citadas}

ARNAO, Antonio: Discursos leídos ante la academia española en la recepción pública de don Antonio Arnao el día 30 de marzo de 1873, Madrid, Imprenta, fundición y estereotipia de don Juan Aguado, 1873.

ARNAO, Antonio: Dramas líricos, Madrid, Medina y Navarro, 1875.

ARNAO, Antonio: "Las naves de Cortés, cuadro lírico", Revista Europea, Madrid, 22 de marzo de 1874, año I, tomo I, no 4, pp. 103-105. Disponible en web:

$<$ http://www.filosofia.org/rev/reu/1874/n004p103.htm> [Última consulta: 01-06-2012]

CHAPÍ, Ruperto: Las naves de Cortés, cuadro lírico en un acto, [1874], MNT 1433 (Almagro, Museo Nacional del Teatro).

CHAPÍ, Ruperto: Las naves de Cortés, cuadro lírico en un acto, [1874], RCSM 1_5632 (Real Conservatorio de Música Superior de Madrid).

GRIER, James: The critical editing of music: history, method and practice, Cambridge University Press, 1996.

IBERNI, Luis: Ruperto Chapí. $2^{\mathrm{a}}$ ed, Madrid, ICCMU, 2009 [2006].

LÓPEZ GómEZ, Santiago: Antonio Arnao, vida y obra de un poeta murciano del siglo XIX, Madrid, Academia Alfonso X el Sabio, 1987.

PASTOR COMín, Juan José: "Les introuvables: Don Lucas del Cigarral o la vindicación de una zarzuela olvidada", Revista de musicología, vol. 30, nº 1, 2007.

PASTOR COMÍN, Juan José: "Fuentes musicales en la obra poética de Gutierre de Cetina", Revista de musicología, vol. 33, nº 1-2, 2010, pp. 63-82. 
Real ACAdemia de Bellas Artes De San Fernando (Madrid). Actas de las sesiones ordinarias y extraordinarias, Acta del día 10 de noviembre de 1873, pp. 581-582. Disponible en web:

$<$ http://bib.cervantesvirtual.com/servlet/SirveObras/p186/235895176503252951434 57/index.htm> [Última consulta: 01-06-2012] 